\title{
Oral Health Impact Profile and Its Relationship with Their Oral Health Status of Beautician Cohorts in Porur, Chennai, India - A Cross Sectional Study
}

\author{
Prashanthy. M. $\mathbf{R}^{1}$, Prabu. $D^{2}$, Rajmohan. $M^{3}$, Bharathwaj. V. $\mathbf{V}^{4}$, Sindhu. $\mathbf{R}^{4}$, \\ Dinesh Dhamodhar ${ }^{3}$, Shreelakshmi. $S^{4}$, Suganya. $\mathbf{P}^{1}$ \\ ${ }^{1}$ Postgraduate Student, Department of Public Health Dentistry, SRM Dental College and Hospital, Ramapuram \\ ${ }^{2}$ Head and Professor of the Department, Department of Public Health Dentistry, SRM Dental College and \\ Hospital, Ramapuram \\ ${ }^{3}$ Reader, Department of Public Health Dentistry, SRM Dental College and Hospital, Ramapuram \\ ${ }^{4}$ Senior Lecturer, Department of Public Health Dentistry, SRM Dental College and Hospital, Ramapuram
}

Corresponding Author: Prabu. D

\begin{abstract}
Aim: To evaluate the oral health impact profile and its relationship with their oral health status among beautician cohorts.

Materials and Methods: A cross sectional study was conducted among 147 beauticians using a simple random sampling technique. The subjects would be taken from the Porur area those who were working in the beauty parlour as a beautician. An individual interview was held, and they got a dental check-up. Oral health status was measured by WHO Proforma 2013 modification. Oral health quality of life was assessed by oral health impact profile (OHIP14) questionnaire. Sociodemographic data were collected and questions regarding oral hygiene measures and habits. As for data analysis, chisquare test was utilized.
\end{abstract}

Results: All scores showed associations with self-rated oral health quality of life and dissatisfaction with oral health status. The dentition status and gingivitis showed statistically significant with oral health impact profile (OHIP-14)

Conclusion: The study reveals that the impact of oral health does not have association with oral health problems, whereas perceived satisfaction with oral health has a better association with clinical indicators. We should motivate the oral hygiene practices among beautician cohorts.
Keywords: Oral health impact profile, Oral health status, Oral health problems, dental diseases, gingivitis, periodontitis, dental caries, quality of life

\section{INTRODUCTION}

Oral health illnesses can influence the quality of life, such as functional, disability, psychosocial and psychological features of adults. Oral health was not parted from the respite of the body. Discomfort and distress from oral complications that affects consumption, communication, sleeping, quality of life and well-being. Thus, the association between clinical indicators and prevalent patient selfreports about their mouth are important for oral health ${ }^{1}$

Responsiveness, or the ability of a health status measurement tool to detect clinically important changes over time is a critical requirement of an outcome measure (and indeed, the OHIP-14 was originally intended to assess long-term effects on OHRQoL). To date, little evidence exists for the responsiveness of OHIP-14 to clinical change over time. OHIP-14 was able to detect modest change in Oral health related quality of life (OHRQoL) and that relatively large samples would be required to detect minimally important clinical differences (defined as five-point scale) $^{2,3}$. 
The data could be inquired about oral illness using only clinical signs, which have been aided as a source for oral health position and estimation of management needs. The knowledge of symptoms and diseases would affect the daily activities and quality of life was also very necessary and notified the serious limitations of using clinical indicators ${ }^{4,5}$. Oral health-related quality of life is defined as an individual's assessment of how the following affect his or her wellbeing: functional factors, psychological factors, social factors, and experience of pain/discomfort in relation to orofacial concerns. Oral diseases such as dental caries and periodontal disease are highly prevalent ${ }^{6,7}$.

The beautician cohorts are authorized to perform corrective medications to the hair, skin, and nails. This can be ventured into different parts including trimming and synthetically treating hair, substance hair evacuation, style patterns, wigs, nails and healthy skin, and hair examination, unwinding methods including head, neck, scalp, hand and feet fundamental back rub and aromatic healing practices.Spartan caries undermines from beautician cohorts quality of life: they experienced the pain, distress, and defect, desperate and prolonged infections, eating and sleep disturbance as well as advanced threat of hospitalization, and loss of pay with the subsequently weakened ability to work $^{8,9,10}$

This study was assessed the beautician cohorts as an effect on their oral health problems due to dental caries, gingivitis, periodontitis, mucosal lesions. Hence this study was evaluated the impact on oral health status and its relationship with oral health quality of life.

\section{MATERIALS AND METHOD}

The cross-sectional study was conducted among 146 beautician cohorts using a simple random sampling technique within the period of December 2019 to February 2020, to determine the Oral health related quality of life and oral health status.
The study subjects would be taken from the Porur area those who were working in the beauty parlour as a beautician. The study evaluated the oral health status measured by WHO Proforma and oral health related quality of life was assessed by oral health impact profile (OHIP-14) questionnaire. The objective of the study was to evaluate the oral health impact profile and its relationship with their oral health status among beautician cohorts find out if there is any association between oral health impact profile (OHIP-14) behaviour and oral health status. The beautician who was worked in the beauty parlour were included in the study, following the fulfillment of the inclusion and exclusion criteria. Following the recruitment of the study subjects, a structured questionnaire of OHIP-14 and WHO Proforma were used to assess the oral health status. There are seven domains in the OHIP-14 questionnaires based on the functional limitation, Physical pain, psychological discomfort Psychological disability, Physical disability, Social disability, Handicap. In the OHIP 14 questionnaire, participants were asked to rate in a Likert -type response scale regarding the frequency of oral health problems which affected the daily life. The responses were coded as very often, quite often, sometimes, hardly ever, and never. The severity of impact was the sum of the responses whereby higher the score, poorer the quality of life. The Cronbach alpha value for OHIP-14 was 0.95. As for data analysis, IBM.SPSS statistics software 23.0 Version, to describe about the data descriptive statistics frequency analysis, percentage analysis was used. To find the significance in categorical data Pearson ChiSquare test was utilized.

\section{INCLUSION CRITERIA}

- A person who was willing to participate in this study were included

- A physically well-being individuals were included

- At least 20 number of teeth should be present 
Prashanthy. M. R et.al. Oral health impact profile and its relationship with their oral health status of beautician cohorts in Porur Chennai, India - a cross sectional study.

\section{EXCLUSION CRITERIA}

- Subjects those who were taking on any type of NSAIDS, painkiller drugs were not included

- Subjects undergoing for orthodontic treatment were not included

- Subjects with systemic diseases were not included

- If the beauty parlour closed at the time of visit were not included

\section{RESULTS}

Table 1: Association between the gender and oral health component

\begin{tabular}{|l|l|l|l|}
\hline \multicolumn{2}{|l|}{ Oral health component } & $\begin{array}{l}\text { Frequency (n-146) } \\
\text { Percentage (\%) }\end{array}$ & $\begin{array}{l}\text { p- } \\
\text { value }\end{array}$ \\
\hline \multirow{2}{*}{ Dental caries } & Present & $125(85.6 \%)$ & $<0.05^{*}$ \\
\cline { 2 - 3 } & $\begin{array}{l}\text { Not } \\
\text { present }\end{array}$ & $21(14.4 \%)$ & \\
\hline \multirow{2}{*}{$\begin{array}{l}\text { Periodontal } \\
\text { disease }\end{array}$} & Present & $112(76.7 \%)$ & $<0.05^{*}$ \\
\cline { 2 - 3 } & $\begin{array}{l}\text { Not } \\
\text { present }\end{array}$ & $34(23.3 \%)$ & \\
\hline Gingivitis & Present & $131(89.7 \%)$ & $<0.05^{*}$ \\
\cline { 2 - 3 } & $\begin{array}{l}\text { Not } \\
\text { present }\end{array}$ & $15(10.3 \%)$ & \\
\hline Erosion & Present & $32(21.9 \%)$ & \multirow{3}{*}{$<0.05^{*}$} \\
\cline { 2 - 3 } & $\begin{array}{l}\text { Not } \\
\text { present }\end{array}$ & $114(78.1 \%)$ & \\
\hline Fluorosis & Present & $9(6.1 \%)$ & \\
\cline { 2 - 3 } & $\begin{array}{l}\text { Not } \\
\text { present }\end{array}$ & $137(93.9 \%)$ & \\
\hline
\end{tabular}

Table 1shows the association between the gender and oral health component among beauticians. It depicts the $85.6 \%$ of people had decayed teeth, $76.6 \%$ of people had periodontal diseases whereas fluorosis was not presented with $93.9 \%$ of beauticians.

Table 2: Differences in mean number of decayed, missing, filled teeth between males and females

\begin{tabular}{|c|c|c|c|c|}
\hline $\begin{array}{l}\text { Caries } \\
\text { index }\end{array}$ & Gender & Mean & $\begin{array}{l}\text { Std. } \\
\text { Deviation }\end{array}$ & $\begin{array}{l}\text { p } \\
\text { value }\end{array}$ \\
\hline \multirow{2}{*}{$\begin{array}{l}\text { Decayed } \\
\text { teeth }\end{array}$} & Male & 1.67 & .895 & \multirow[t]{2}{*}{$0.026^{*}$} \\
\hline & Female & 1.10 & .779 & \\
\hline \multirow{2}{*}{$\begin{array}{l}\text { Missing } \\
\text { teeth }\end{array}$} & Male & .89 & .094 & \multirow[t]{2}{*}{$0.018 *$} \\
\hline & Female & .01 & .077 & \\
\hline \multirow{2}{*}{$\begin{array}{l}\text { Filled } \\
\text { teeth }\end{array}$} & Male & 1.91 & .301 & \multirow[t]{2}{*}{$0.029 *$} \\
\hline & Female & .09 & .304 & \\
\hline
\end{tabular}

Table 2 shows the t-test of independent means for differences in mean number of decayed, missing, filled teeth and surfaces between males and females. It depicts the statistically significant $(\mathrm{p}<0.026)$ of people had decayed teeth, missing teeth were also statistically significant $(\mathrm{p}<0.018)$.

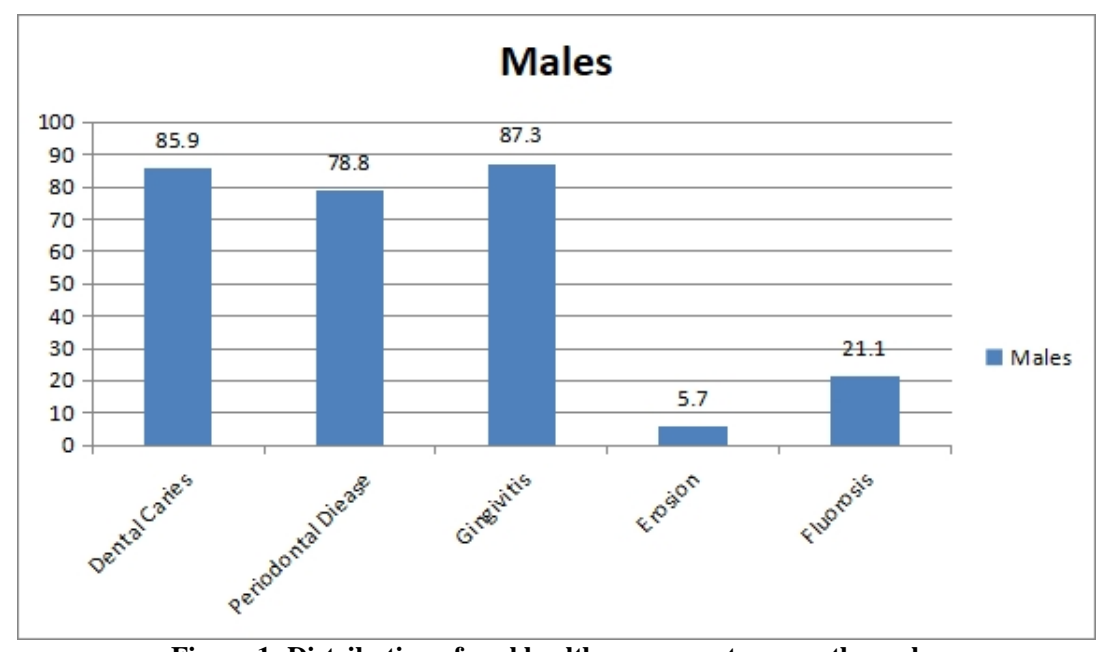

Figure 1: Distribution of oral health component among the males

Figure 1 shows the distribution of oral health component among males. It depicts the $85.9 \%$ of male beauticians had decayed teeth, $78.8 \%$ of male had periodontal diseases whereas fluorosis was not presented with $78.9 \%$ of male beauticians.
Figure 3 shows the distribution of oral health component among females. It depicts the $85.3 \%$ of females had decayed teeth, $74.6 \%$ of females had periodontal diseases whereas fluorosis was not presented with $88 \%$ of female beauticians. 
Prashanthy. M. R et.al. Oral health impact profile and its relationship with their oral health status of beautician cohorts in Porur Chennai, India - a cross sectional study.

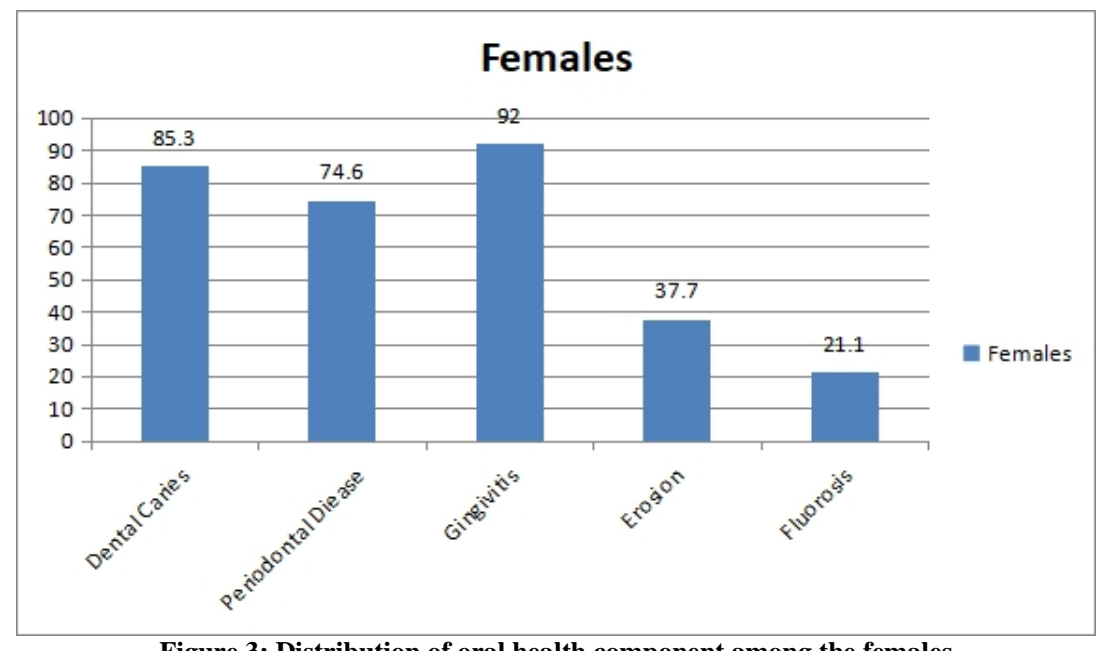

Figure 3: Distribution of oral health component among the females

TABLE-3 ASSOCIATION BETWEEN ORAL HEALTH IMPACT PROFILE AND GINGIVITIS

\begin{tabular}{|l|l|l|l|l|l|}
\hline \multirow{2}{*}{ Oral health impact profile(14)Overall score } & \multicolumn{2}{|l|}{ GINGIVITIS } & \multirow{2}{*}{ Total } & \multirow{2}{*}{ p-value } \\
\cline { 2 - 5 } & Less than or equal to 4 tooth & More than 4 tooth & & \\
\cline { 2 - 5 } & Less than or equal to 28 & 55 & 24 & 79 & \\
\cline { 2 - 5 } & More than 28 & 36 & 31 & 67 & 0.048 \\
\hline
\end{tabular}

Table -3 shows that the association between oral health impact profile (OHIP-14) and dental gingivitis ( $\mathrm{p}$ 0.04) were statistically significant.

TABLE 4 ASSOCIATION BETWEEN ORAL HEALTH IMPACT PROFILE AND DENTAL CARIES

\begin{tabular}{|l|l|l|l|l|}
\hline \multicolumn{2}{|l|}{} & \multicolumn{2}{l|}{ DENTAL CARIES } & \\
\cline { 2 - 5 } & Less than or equal to 5 tooth & More than 5 tooth & Total & p-value \\
\hline \multirow{2}{*}{$\begin{array}{l}\text { Oral health impact profile (14) } \\
\text { Overall score }\end{array}$} & Less than or equal to 28 & 44 & 35 & 79 \\
\cline { 2 - 5 } & More than 28 & 35 & 32 & 636 \\
\hline Total & 79 & 67 & 67 \\
\hline
\end{tabular}

Table -4 shows that the association between oral health impact profile (OHIP14) and dental caries ( $\mathrm{p}$ 0.03) were statistically significant

\section{DISCUSSION}

The concept of health has gone through a paradigm shift in the recent years. The medical health model is greatly expanded by the addition of the psychosocial aspects of health. Instead of interpreting health as a state of absence of organic disease or pathological processes in the past, health is now interpreted as a state of complete physical, mental, and social well-being, and not merely the absence of disease or infirmity. ${ }^{11}$ This emerged out of a growing recognition that traditional clinical measures of health need to be supplemented by data obtained from patients and/or persons that capture their experiences and concerns. This is accurate for dentistry too, where there has been a mushrooming of instruments and scales to evaluate what has come to be known as OHRQoL and/or the QoL of patients with various oral conditions. ${ }^{12}$ The study was performed to described the Oral health related quality of life and it's associated with oral health variables in Porur area those who were working in the beauty parlour as a beautician.

In the current study, $48.6 \%$ of males and $51.4 \%$ of females were included. This shows that females were more prone for oral health diseases than males, which was also reported by Lawrence et $\mathrm{al}^{13}$ and Navin et $\mathrm{al}^{14}$ and females experienced more severe impacts of oral disorders on everyday life than males. Due to the fact that more females were working as a beautician than males in the beauty parlour

In the current study, around $26 \%$ of the beauticians, occasionally had pain in the mouth. Similar in Shailee et $\mathrm{al}^{15}$ study 
reported that $22.8 \%$ of the subjects occasionally had pain in the mouth. This may be due to the fact that presence of oral health problems among the study participants.

In this study, subjects had occasionally unable to function was $11.6 \%$ which is less than $23.4 \%$ as reported from the study conducted by Hodačová et al ${ }^{16}$. The difference may be because gender of this study population while the gender and age group was varied, and the people of younger age group are known to cite a lower impact of oral health condition and it determined the quality of life.

The present study reported that $14.4 \%$ of subjects had occasionally uncomfortable to eat foods, similar in Shailee et $\mathrm{al}^{15}$ study stated that $12.2 \%$ of subjects had uncomfortable to eat foods and was reported mostly by those having one or more decayed teeth and this finding was consistent with the findings of Adulyanon et $\mathrm{al}^{17}$ study. The prevalence of functional limitation and psychological discomfort (response categories fairly often or very often) was $4.6 \%$ and $8.2 \%$ and was mostly reported by those having missing teeth and these findings are consistent with the findings of Slade $\mathrm{GD}^{18}$. Out of 351 study subjects, there were $45.02 \%$ males and $54.98 \%$ females which can be explained by the fact that more females normally attend dental practice and gender based difference are quite apparent, with the utilization of dental care, services and treatment outcomes ${ }^{11}$.

The present study included both clinical markers of oral health status and a multi-item OHRQoL scale was one of the most significant. The measure of OHRQoL was strongly linked to clinical markers of oral health status. Furthermore, a personal interview was preferred over the original self-reported form that used the OHIP-14 in a questionnaire format could be result in lower completion rates.

\section{Limitations}

The limitations being the possibility of measurement bias while recording the questionnaire of oral health impact profile from beautician cohorts as a result, the findings cannot be applied to the broader population. The results in terms of the gender and oral health status factors might have been influenced by the small sample size. In addition, the study was crosssectional, and other aspects were not taken into account. As a result, further research with specific populations is required, particularly in various social and cultural settings, as these factors have a significant influence in both oral hygiene status and its impact on quality of life.

\section{CONCLUSION}

The study reveals that the impact of oral health does not have association with oral health problems, whereas perceived satisfaction with oral health has a better association with clinical indicators. We should motivate the oral hygiene practices among beautician cohorts

\section{Acknowledgement: None}

\section{Conflict of Interest: None}

\section{Source of Funding: None}

\section{Ethical Approval: Approved}

\section{REFERENCES}

1. Locker D, Miller Y. Evaluation of subjective oral health status indicators. Journal of public health dentistry. 1994 Jun; 54 (3):167-76.

2. Sheiham A. Oral health, general health and quality of life. Bull World Health organ 2005:83(9):644

3. Slade GD, Spencer AJ. Development and evaluation of the Oral Health Impact Profile. Community Dent Health. 1994; 11:3-11.

4. Cohen LK. The emerging field of oral health-related quality of life outcomes research. Measuring oral health and quality of life. 1996:1-0 
5. Naito M, Yuasa H, Nomura Y, Nakayama T, Hamajima N, Hanada N. Oral health status and health-related quality of life: a systematic review.Journal of Oral science. 2006; 48: 1-7

6. Hebling E, Pereira AC. Oral health-related quality of life: a critical appraisal of assessment tools used in elderly people. Gerontology. 2007; 24: 151-161.

7. Allen PF, McMillan AS, Walshaw D, Locker D. A comparison of the validity of generic- and disease-specific measures in the assessment of oral health-related quality of life. Community Dent Oral Epidemiol. 1999;27:344-52

8. Slade GD. Measuring oral health and quality of life. Chapel Hill. 1997;3.

9. Locker D, Jokovic A, Clarke M. Assessing the responsiveness of measures or oral health-related quality of life. Community Dent Oral Epidemiol 2004;32:10-8.

10. Ingle hart MR, Bagramian RA. (Editors). Oral health-related quality of life. Chicago:Quintessence publishing , 2002; pp. 1-6.

11. Wade DT, Halligan PW Do biomedical models of illness make for good healthcare systems? BMJ: Br Med J 2004;329:1398401.

12. Shamrany AM Oral health-related quality of life: A broader perspective. East Mediterr Health J 2006;12:894-901

13. Lawrence HP, Thomson WM, Broadbent JM, Poulton R. Oral health-related quality of life in a birth cohort of 32-year olds. Community Dentistry and Oral Epidemiology. 2008; 36: 305-316.
14. Ingle NA, Chaly PE, Zohara CK. Oral Health related quality of life in adult population attending the outpatient department of a hospital in Chennai, India. Journal of International Oral Health. 2010; 2: 45-52.

15. Fotedar S, Sharma KR, Fotedar V, Bhardwaj V, Chauhan A, Manchanda K. Relationship between oral health status and oral health related quality of life in adults attending HP Government Dental College, Shimla, Himachal Pradesh--India. Oral health and dental management. 2014 Sep 1;13(3):661-5.

16. Hodačová L, Šmejkalová J, Čermáková E, Slezák R, Jacob V, Hlaváčková E. Oral health-related quality of life in Czech population. Central European Journal of Public Health. 2010; 18: 76-80.

17. Adulyanon S, Vourapukjaru J, Sheiham A. Oral impacts affecting daily performance in a low dental disease Thai population. Community Dentistry and Oral Epidemiology. 1996; 24: 385-389.

18. Slade GD, Nuttall N, Sanders AE, Steele JG, Allen PF, Lahti S. Impacts of oral disorders in the United Kingdom and Australia. British Dental Journal. 2005; 198: 489-493

How to cite this article: Prashanthy. M. R, Prabu. D, Rajmohan. M et.al. Oral health impact profile and its relationship with their oral health status of beautician cohorts in Porur, Chennai, India - a cross sectional study. International Journal of Research and Review. 2021; 8(11): 211-216. DOI: https://doi.org/10.52403/ijrr. 20211128 